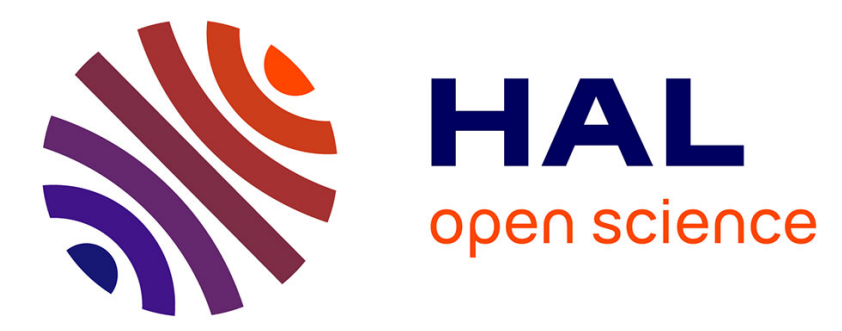

\title{
Manic switches induced by antidepressants: an umbrella review comparing randomized controlled trials and observational studies
}

\author{
N. Allain, C. Leven, B. Falissard, J.-S. Allain, Jean-Marie Batail, E. Polard, \\ F. Montastruc, Dominique Drapier, Florian Naudet
}

\section{To cite this version:}

N. Allain, C. Leven, B. Falissard, J.-S. Allain, Jean-Marie Batail, et al.. Manic switches induced by antidepressants: an umbrella review comparing randomized controlled trials and observational studies. Acta Psychiatrica Scandinavica, 2017, 135 (2), pp.106-116. 10.1111/acps.12672 . hal-01484968

\section{HAL Id: hal-01484968 \\ https://hal-univ-rennes1.archives-ouvertes.fr/hal-01484968}

Submitted on 28 Mar 2017

HAL is a multi-disciplinary open access archive for the deposit and dissemination of scientific research documents, whether they are published or not. The documents may come from teaching and research institutions in France or abroad, or from public or private research centers.
L'archive ouverte pluridisciplinaire HAL, est destinée au dépôt et à la diffusion de documents scientifiques de niveau recherche, publiés ou non, émanant des établissements d'enseignement et de recherche français ou étrangers, des laboratoires publics ou privés. 


\section{Acta Psychiatrica Scandinavica}

\section{Manic switches induced by antidepressants. An umbrella review comparing randomised controlled trials and observational studies.}

\begin{tabular}{|c|c|}
\hline Journal: & Acta Psychiatrica Scandinavica \\
\hline Manuscript ID & ACP-2016-6032.R1 \\
\hline Manuscript Type: & Meta-analysis \\
\hline Date Submitted by the Author: & 25-Oct-2016 \\
\hline Complete List of Authors: & $\begin{array}{l}\text { ALLAIN, Nathalie; Centre hospitalier Guillaume Regnier, Academic } \\
\text { Psychiatry Department; EA } 4712 \text { Behavior and Basal Ganglia, CHU Rennes, } \\
\text { Rennes } 1 \text { University } \\
\text { LEVEN, Cyril; Laboratory of Experimental and Clinical Pharmacology, } \\
\text { Rennes } 1 \text { University, Faculty of Medicine; INSERM CIC-P 1414, Clinical } \\
\text { Investigation Center, CHU Rennes, Rennes } 1 \text { University } \\
\text { Falissard, Bruno; CESP, Univ.Paris-Sud, Université Paris-Saclay, UVSQ, } \\
\text { INSERM U1178, Maison de Solenn } \\
\text { ALLAIN, Jean-Sébastien; Rennes University Hospital, Department of } \\
\text { Internal Medicine } \\
\text { BATAIL, Jean-Marie; Centre hospitalier Guillaume Regnier, Academic } \\
\text { Psychiatry Department; EA } 4712 \text { Behavior and Basal Ganglia, CHU Rennes, } \\
\text { Rennes } 1 \text { University } \\
\text { POLARD, Elisabeth; Pharmacovigilance, Pharmacoepidemiology and Drug } \\
\text { Information Center, Rennes University Hospital, Department of } \\
\text { Pharmacology; Pharmacoepidemiology team (CTAD-PEPI), Rennes } \\
\text { University Hospital } \\
\text { MONTASTRUC, François; Midi-Pyrénées centre for pharmacovigilance, } \\
\text { pharmacoepidemiology and drug information. INSERM U 1027 } \\
\text { pharmacoepidemiology research unit, Department of medical and clinical } \\
\text { pharmacology } \\
\text { Drapier, Dominique; Centre hospitalier Guillaume Regnier, Academic } \\
\text { Psychiatry Department; EA } 4712 \text { Behavior and Basal Ganglia, CHU Rennes, } \\
\text { Rennes } 1 \text { University } \\
\text { Naudet, Florian; INSERM CIC-P } 1414, \text { Clinical Investigation Center, CHU } \\
\text { Rennes, Rennes } 1 \text { University; Meta-Research Innovation Center at Stanford } \\
\text { (METRICS), Stanford University }\end{array}$ \\
\hline Keywords: & Meta analysis, Randomized Controlled Trial, Affective disorders, Depression \\
\hline
\end{tabular}


Manic switches induced by antidepressants. An umbrella review comparing randomised controlled trials and observational studies.

ALLAIN, Nathalie (MD) ${ }^{1,2}$

LEVEN, Cyril (PharmD) ${ }^{3,4}$

FALISSARD, Bruno (MD, PhD) ${ }^{5}$

ALLAIN, Jean-Sébastien (MD) ${ }^{6}$

BATAIL, Jean-Marie (MD) ${ }^{1,2}$

POLARD, Elisabeth (PharmD) ${ }^{7,8}$

MONTASTRUC, François (MD) ${ }^{9}$

DRAPIER, Dominique (MD, PhD) $)^{1,2}$

NAUDET, Florian (MD, PhD) $)^{4,10}$

1. Academic Psychiatry Department, Centre Hospitalier Guillaume Régnier, Rennes, France;

2. EA 4712 Behavior and Basal Ganglia, CHU Rennes, Rennes 1 University, Rennes, France.

3. Laboratory of Experimental and Clinical Pharmacology, Rennes 1 University, Faculty of Medicine, Rennes, France; 
4. INSERM CIC-P 1414, Clinical Investigation Center, CHU Rennes, Rennes 1 University, Rennes, France.

5. CESP, Univ.Paris-Sud, Université Paris-Saclay, UVSQ, INSERM U1178, Maison de Solenn, 94 Bd de Port Royal, 75679, Paris Cedex 14, France

6. Department of Internal Medicine, Rennes University Hospital, Rennes, France

7. Department of Pharmacology, Pharmacovigilance, Pharmacoepidemiology and Drug Information Center, Rennes University Hospital, Rennes, France.

8. Pharmacoepidemiology team (CTAD-PEPI), Rennes University Hospital, Rennes, France.

9. Department of medical and clinical pharmacology, Midi-Pyrénées centre for pharmacovigilance, pharmacoepidemiology and drug information. INSERM U 1027 pharmacoepidemiology research unit, Toulouse, France.

10. Meta-Research Innovation Center at Stanford (METRICS), Stanford University, 1070 Arastradero Road, Palo Alto, CA, 94304, USA.

Corresponding author

Centre hospitalier Guillaume Regnier, CHGR

108 avenue du général Leclerc

Rennes, FR 35703

Phone: (+33) 299333900

Fax: (+33) 299333996

E-mail: nathalie.leclanche@hotmail.fr 


\section{ABSTRACT}

\section{Objective}

We aimed to explore whether the prevalence of manic switch was underestimated in randomised controlled trials (RCTs) compared to observational studies (OSs).

\section{Method}

Meta-analyses and simple and systematic reviews were identified by two reviewers in a blinded, standardised manner. All relevant references were extracted to include RCTs and OSs that provided data about manic switch prevalence after antidepressant treatment for a major depressive episode. The primary outcome was manic switch prevalence in the different arms of each study. A meta-regression was conducted to quantify the impact of certain variables on manic switch prevalence.

\section{Results}

57 papers (35 RCTs and 22 OSs) were included in the main analysis. RCTs underestimated the rate of manic switch $[0.53(0.32$ to 0.87$)]$. Overestimated prevalence was related to imipraminics [1.85 (1.22 to 2.79)]; to Serotonin-Norepinephrine Reuptake Inhibitors [1.74 (1.06 to 2.86)]; and to other classes of drugs [1.58 (1.08 to 2.31)], compared to placebo treatment. The prevalence of manic switch was lower among adults than among children $[0.2$ (0.07 to 0.59$)]$; and higher [20.58 (8.41 to 50.31)] in case of bipolar disorder.

\section{Conclusion}

Our results highlight an underestimation of the rates of manic switch under antidepressants in RCTs compared to the rates observed in observational studies. 


\section{Significant outcomes}

We found a difference in reported manic switch rates under antidepressants between Randomised Controlled Trials (RCTs) and observational studies (OS), with an underestimation in RCTs (or an overestimation in OS).

Overestimated prevalence of manic switch was related to imipraminics, to SerotoninNorepinephrine Reuptake Inhibitors and to other classes of drugs, in comparison with placebo treatment.

The prevalence of manic switch was lower among adults than children and higher in case of bipolar disorder.

\section{Limitations}

We cannot conclude formally as to whether there is an underestimation in RCTs or an overestimation in OSs.

We disrupted the randomisation with our meta-regression model, so that caution is required for comparisons between treatments, and any differences found can, in part, be explained by an indication bias.

\section{Ethical statement}

This article does not include any studies involving human participants or animals performed by any of the authors. 


\section{INTRODUCTION}

Recently, there has been a debate about psychiatric drugs, which have been accused of doing more harm than good in many situations (1). While these drugs have gone through strict regulatory controls, their risk-benefit balance is nevertheless still a subject of controversy, particularly in terms of Adverse Drug Reactions (ADRs) over the long term (2-4). This state-of-the-art fundamentally questions the evaluation process of the risk-benefit balance of these drugs, which is usually assessed, in a first step, using Randomised Controlled Trials (RCTs). However, it is well known that these studies are underpowered to detect rare adverse events when they are less frequent than the occurrence of the primary outcome of the study (generally response) $(5 ; 6)$. Less is known on whether RCTs might also underestimate the prevalence of certain ADRs (7) because of $1 /$ an overselection of "supranormal" and healthy participants and 2/ a limited follow-up duration. Observational studies are thus thought to be complementary, in a second step, to explore the prevalence of ADRs in a real-life setting.

We chose to explore this issue by focusing on antidepressants, the effectiveness of which is still controversial, and on prevalence of manic switch as an outcome. In the management of antidepressant pharmacotherapy, preventing this ADR is an important issue for patients. Indeed, it is frequently a "serious" ADR, often resulting in hospitalisation (8). While it is not infrequent in day-to-day clinical practice, information on its prevalence is conflicting across the literature (simple or systematic reviews and meta-analyses) with no consensus and even very heterogeneous estimations. In fact, causality assessments (“imputability" or "imputation") for this ADR are often controversial. Clinical judgment, history of mood disorder, family psychiatric history, the existence of a hyperthymic temperament, time-lapse after a prescription of antidepressant and evolution could all explain such discrepancies. All these characteristics might be very different across RCTs and observational studies. We thus designed an umbrella review on aggregated data to compare manic switch prevalence between RCTs and observational studies and to reconcile the apparently divergent conclusions observed in the literature by modeling the prevalence of manic switch according to the different study designs, in a meta-epidemiological perspective.

\section{METHOD}

The methods of this umbrella review of aggregated data and the inclusion criteria were specified in advance and documented in a protocol (Systematic Reviews Registration - PROSPERO 2013:CRD42013004383). 


\section{Eligibility criteria}

We aimed to explore discrepancies in prevalence of manic switch reported in simple, systematic reviews and meta-analyses, so these studies were searched for in a first step. In a second step, references in these studies that met the following selection criteria were extracted.

\section{Types of participant}

We reviewed all studies involving children, adolescents and adults with a diagnosis of unipolar or bipolar depression (according to international classifications such a DSM-IV or according to the severity of symptoms measured with depression scales), and treated with antidepressants. Studies involving patients with other psychiatric or medical comorbidities were considered.

\section{Types of intervention}

We focused our attention on antidepressant treatment (Selective Serotonin Reuptake Inhibitor (SSRI), SerotoninNorepinephrine Reuptake Inhibitors (SNRI), Imipraminics (IP), other classes of antidepressant, all classes). Where appropriate, in RCTs, we also extracted data about placebo arms. Patients treated with MAOIs (monoamine oxidase inhibitors) were excluded from this review, because these drugs are currently rarely used in clinical practice (9).

\section{Types of outcome}

The primary outcome was the rate of manic switch reported in each arm of each study.

\section{Types of study}

In this review, we considered RCTs and observational cohorts (longitudinal non-randomised and non-blinded studies) that provided data about rates of manic switch after antidepressant treatment. Only study reports in English, French and Spanish were included.

\section{Search strategy}

Eligible studies were identified from PubMed/Medline, the Cochrane library, and Embase, including congress abstracts. We searched all simple reviews, systematic reviews or meta-analyses published between 1990 and 2013 to identify all trials included in these studies. We used the following algorithm: (mania OR manic OR mood) AND switch AND ((Clinical Trial[ptyp] OR Meta-Analysis[ptyp] OR Review[ptyp] OR systematic[sb] 
OR Clinical Trial, Phase I[ptyp] OR Clinical Trial, Phase II[ptyp] OR Clinical Trial, Phase III[ptyp] OR Comparative Study[ptyp] OR Controlled Clinical Trial[ptyp] OR Clinical Trial, Phase IV[ptyp])) AND ("1990/01/01"[PDAT] : "2013/12/31"[PDAT])). We considered every additional clinical study on manic switch identified with the previous search.

\section{Study selection}

Study selection was performed in two steps. In a first step, meta-analyses, simple and systematic reviews were identified in a blinded standardised manner by two reviewers (CL, FN). In a second step, all relevant references were extracted (NA, FN). A comparison across all the individual studies was performed, checking authors, treatment comparisons, sample sizes and outcomes, to avoid duplicates and compilations of data from several reports on the same study. Thus no individual study was counted more than once.

\section{Assessment of methodological quality}

Each paper was assessed for methodological quality prior to inclusion in the review, using two appropriate standardized critical appraisal instruments (10), one for RCTs and one for observational studies.

\section{Data collection process}

A data extraction sheet based on the Cochrane Handbook for Systematic Reviews of Interventions guidelines (11) was used. Three reviewers (NA, CL, JSA) performed data extractions. Disagreements were resolved by consensus or through discussion with a fourth reviewer (FN). For each arm of each study included, we extracted information on: 1/ characteristics of the study (type [RCT, observational], year, blinding, duration), 2/ characteristics of trial participants (number of patients included in the analysis, diagnosis [unipolar or bipolar or both], age classes [children/ adolescents or adults or both], proportion of women, initial severity, previous antidepressant resistance (resistance to at least two distinct classes), recruitment [inpatients or outpatients or both]), 3/ type of intervention (treatment [SSRI, SNRI, IP, other classes, all classes, placebo], duration of treatment), 4/outcome measure (rate of manic switch, type of evaluation of manic switch).

\section{Data synthesis}

To adjust our comparison of observational studies and randomised controlled trials on identified sources of heterogeneity, and to quantify the impact of certain variables on the manic switch rate (MSR), we performed a meta-regression. The dependent variable was MSR and the following pre-specified explanatory variables were 
considered: study type; type of treatment; diagnosis; year of publication; study duration; age classes; proportion of women, patient recruitment.

This meta-regression was performed by using a random-coefficient Poisson model with the "study" factor specified as a random effect. Exp(betas) are reported with their 95\% confidence interval. Exp(betas) can be interpreted as "adjusted rate ratios".

Multiple imputation of missing data was performed using a Gibbs sampler.

To assess the robustness of our results, sensitivity analyses were performed: 1) by removing each arm in turn, and 2) using quality assessment to adjust the weight of a given study.

Analyses were performed using R (11) and the libraries meta (Schwarzer G), lme4 (Maechler D), and MICE (Van Buuren S, Groothuis-Oudshoorn K). Results are presented according to PRISMA statements (Preferred Reporting Items for Systematic Reviews and Meta-Analyses) (12).

\section{Minor changes to our initial protocol}

We planned to consider age and baseline severity as continuous variables, but there was too much missing data. We replaced these variables in our model by the following proxies: age class and previous antidepressant resistance.

In response to one reviewer's comment, we conducted a post hoc analysis by adding an interaction term to the main model between study design (observational or RCT) and illness (MDD or bipolar disorder or both).

\section{RESULTS}

\section{Study selection}

The search of Medline, Cochrane and Embase databases provided a total of 1195 citations, respectively 486,256 and 453 citations. After adjusting for duplicates, 971 remained. Of these, 950 studies were discarded because, after reviewing the abstracts, it appeared that these papers did not meet the eligibility criteria. Our first search identified 21 reviews and/or meta-analyses. In these reviews, 101 references were extracted. After reviewing full texts of these references in detail, it appeared that 44 articles did not meet the inclusion criteria as described. Our second search step thus provided 57 studies, which were included in the quantitative review. A PRISMA chart detailing the study selection process for RCTs and observational studies is given in Figure 1. 


\section{Study characteristics and risk of bias within studies}

The studies selected were 35 randomised controlled trials and 22 observational studies (see Web appendix for references) involving respectively 6244 and 76544 patients in 66 and 40 arms. A summary of study methodology and quality is given in Table 1 . The description of arms is detailed in Table 2.

\section{Results from individual studies and synthesis of results}

As expected, using the Q statistic, significant heterogeneity was detected for: 1/ active treatment effect in RCTs, 2/ placebo effect in RCTs, and 3/ active treatment effect in observational studies. The Forest plot presenting individual arm results is reported in Figure 2.

The meta-regression (Table 3) shows that RCTs underestimate the rate of manic switch compared to observational studies $[(\exp ($ beta $)=0.53(0.32$ to 0.87$)]$. Overestimated prevalence was attributable to IP $[\exp ($ beta $)=1.85(1.22$ to 2.79$)] ;$ to $\mathrm{SNRI}[\exp ($ beta $)=1.74(1.06$ to 2.86$)]$; and to other classes [exp(beta) $=$ $1.58(1.08$ to 2.31$)]$, compared to placebo treatment. Regarding the patients, the prevalence of manic switch was lower in adults than in children and adolescents $[\exp ($ beta $)=0.2(0.07$ to 0.59$)]$; and higher $[\exp ($ beta $)=20.58$ (8.41 to 50.31)] in bipolar disorder. There was a decrease in manic switch prevalence $[\exp ($ beta $)=0.97(0.96$ to $0.98)]$ for each year of study publication and an increase $[\exp ($ beta $)=1.01$ ( 1 to 1.03$)]$ for each additional week of duration.

\section{Additional analyses}

Sensitivity analyses taking quality into account showed the robustness of our estimation for study type, antidepressant class, diagnosis and age class. Sensitivity analysis removing each arm in turn found 4 studies (1316) that could have impact estimations of coefficients concerning treatment (SNRI, other classes) and age classes (both). Results from the sensitivity analysis are presented in detail in the Web appendix.

In the post-hoc analysis exploring the interaction term between study design (observational or RCT) and the illness (MDD or bipolar disorder or both), the difference between RCT and observational studies appeared still present in MDD patients $(\exp ($ betas $)=0.27[0.09-0.76])$ and the interaction term, although not significant, suggested that this difference might be less pronounced when the studies involved both bipolar disorder and MDD patients (interaction: $\exp ($ betas $)=1.29[0.18-9.19])$ or only bipolar patients (interaction: $\exp ($ betas $)=2.48$ [0.79-7.83]). 


\section{DISCUSSION}

\section{Summary of evidence}

Our results highlight a difference in rates of manic switch after antidepressants between RCTs and observational studies, with an underestimation in RCTs or an overestimation in OSs. This result is stable between the main analysis and the sensitivity analysis, demonstrating its robustness. It has also been suggested in a previous comprehensive review (17). The difference is not trivial; without adjustment it is nearly a 10 percent difference and, after adjustment, the $\operatorname{exp(betas)}$ are in the same order of magnitude as the differences estimated between antidepressants and placebo in our model. In RCTs, inclusion criteria are more restrictive than those in observational studies, which could provide a better reflection of real-life settings. For example, patients with comorbid substance abuse or dependence are often excluded from RCTs. And precisely, comorbid substance abuse or dependence, in particular alcohol, is associated with an increased risk for (hypo) mania during antidepressant use (18). In addition, we found that study duration was associated with an increased risk of manic switch. Patients exposed to antidepressants over a long period are at higher risk for manic switch. RCTs are shorter that observational studies and could underestimate the occurrence of manic switch.

Other study factors associated with significant variations in the rates of manic switch were evidenced with our meta-regression. In our meta-analysis treatment with SNRI, IP or other antidepressants (often bupropion, a psychostimulant) are associated with an increased risk of manic switch compared to placebo, in line with the results in the literature $(19 ; 20)$. Manic switch was also more frequent with all antidepressant classes than with placebo, but this did not reach statistical significance. Manic switch was estimated to be more frequent in bipolar patients, compared to unipolar patients, providing some clear external validity for our model.

In a post-hoc analysis, we found no significant interaction between study design and illness. This might suggest that the difference between observational studies and RCTs is consistent across the different disorders. Nevertheless, the result should be interpreted cautiously since our study might be underpowered to explore this issue.

Interestingly, we identified a decrease in the rate of manic switch for each year of study publication. This result is obtained after adjustment and takes into account the fact that earlier studies used IP and possibly SNRI, and later studies avoided SNRI, and examined the safer SSRIs. First, manic switch is an entity that is somewhat difficult to define from a nosographic perspective and this result could be related to changes in diagnostic 
criteria, and to the changing concept of manic switch. In older studies (21), the psychomotor agitation associated with IP was liable to be labelled as a manic switch, while today the diagnostic criteria are more restrictive. Criteria have changed over time. In the DSM III-R, antidepressant-induced agitation was considered as a real manic episode, while in the DSM IV, it is no longer a subtype of bipolar disorder, but a substance-induced mood disorder. In the present meta-analysis, no study was based on the DSM V criteria. Nonetheless, views have recently changed about manic switch. DSM V adopts the DSM III-R views and adds the following note to the diagnostic criteria for manic episodes: "A full manic episode that emerges during antidepressant treatment but persists at a fully syndromal level beyond the physiological effect of that treatment is sufficient evidence for a manic episode and, therefore, a bipolar I diagnosis". Hypomanic episodes have a similar note in DSM V. These notes seem to widen the concept of bipolar disorder, because patients developing mania or hypomania during antidepressant treatment can be diagnosed as bipolar I or II in DSM V, while they were diagnosed as suffering from substance-induced mood disorder in DSM-IV-TR. Since the so-called "physiological effect of that treatment" is rather vague, it is hard to say to what extent this new definition will broaden the concept of bipolar disorder by including "true" bipolar disorders but also "true" ADRs resulting directly from a given treatment.

Second, the inclusion criteria may have changed across time, resulting in populations with different risks for manic switch. In addition, in the sensitivity analysis, where quality was taken into account, the effect of publication year disappeared suggesting that this effect, and indeed the assessment of manic switch, can be linked to study quality.

We also found an effect of the age class. Adults have a lower risk of manic switch than children and adolescents, which is in agreement with clinical experience (13). Antidepressants should therefore be used with even more caution in this population.

\section{Limitations}

Our method of extracting studies from meta-analyses and reviews about manic switch does not enable an exhaustive review as commonly performed in meta-analysis. This could have led to a biased sample. But this biased sample is a straighforward reflection of the literature. Our aim was indeed to understand the literature on rates of manic switch from a meta-epidemiological perspective.

Our sensitivity analyses identified four studies with an impact on a few coefficient estimations. After careful examination, three of these studies were in fact large (RCT or observational). Their impact on our model 
estimates are thus to a degree to be expected. Nonetheless, the following limitations were identified: $1 /$ in the first observational study (13), even after mailing study authors, it was not confirmed that all participants were depressed, and the proportion of subjects with depression was not clearly defined; 2 / the two other studies (14; 22) were derived from the same program (the STEP-BD program), and there may have been some overlap of subjects in the two studies (i.e. the same subject could have been studied twice). The author was contacted by email and indicated that there was probably not a great deal of overlap between the two studies. The last influential study (16) we identified was a small observational study in children and adolescents, and could only have affected the estimation of coefficients related to age class. Its influence on the other coefficients was not significant.

It should be kept in mind that, to a certain extent, we disrupted randomisation with our meta-regression model, so caution is required for comparisons between treatments, and any differences found can, in part, be explained by an indication bias. Nonetheless, our results are in accordance with the results of the literature $(17 ; 20)$ which is a sign of external validity.

Nevertheless, the main limitation is probably not statistical but rather conceptual, and concerns our interpretation of differences between RCTs and observational studies. While our interpretation is in favor of an underestimation of MSRs in RCTs, one can argue, conversely, that there is an overestimation in observational studies, or that both phenomena are at play here. In observational studies, it may be more difficult to differentiate mania induced by antidepressants and mania arising from the natural course of bipolar disorder or anxious comorbidity. Observational studies are thought to be more representative of "real life", but bias can also contribute to an overestimation of manic switch. On the other hand, the widely discussed GSK Study 329 (2325 ) is good example of underestimation by misreporting of ADRs in RCTs. Additionally, rare ADRs cannot be evidenced in RCTs and only pharmacoepidemiological studies are able to explore them.

\section{Perspective}

Safety is a cornerstone of drug evaluation. The development of evaluation techniques in pharmacology has been linked to safety issues (26) and for instance the focus on efficacy in the 1962 amendments to the Food and Drugs Act after thalidomide aimed to improve safety. The wide adoption of RCTs was intended to promote an appropriate evaluation of the risk-benefit balance of treatments. In practice, RCTs have not proved ideal, since they do not function well for safety assessment purposes. Randomisation can introduce confounding factors 
wherever a treatment and an illness are liable to produce similar or fairly similar adverse events (27) as for example in the case of manic switch in bipolar participants. Secondly RCTs are underpowered to detect adverse events when these events are less frequent than the occurrence of the primary outcome. On the basis of a limited example (manic switch with antidepressants in major depressive disorder), our results suggest a difference in between RCTs and observational studies, but we can't conclude formally whether there is an underestimation in RCTs or an overestimation in OSs. On the other hand, previous work $(28 ; 29)$ suggested that RCTs could overestimate the beneficial effects of antidepressants in major depressive disorder. Overall this suggests that the evidence used for drug approval could lead to a biased estimation of the risk-benefit balance of treatments such as antidepressants. While the extent of any such distortion is still unclear and very hard to explore, it is a crucial issue for meta-research. It could explain distinct points of view and disagreements between trialists and pharmacoepidemiologists, against a backdrop of ideological and/or financial conflicts of interest. Beyond these scientific aspects, this distortion can be of really practical interest for clinicians, who have to cope, in their dayto-day practice, with this area of uncertainty: when choosing a treatment for a given patient, if the clinician chooses to treat him "scientifically" he/she must accept that this is an experiment, and must be aware of what happens for the individual patient. From the patient perspective, we have indeed no better evidence than the patient's experience (30).

\section{CONCLUSION}

\section{Implications for research}

In our umbrella review, we only studied one ADR, and it might be tempting to extrapolate our findings to other ADRs under antidepressants, some of which are still being debated in the literature. For example, in the context of antidepressant trials, a new meta-regression would be interesting to determine whether the rate of suicide under antidepressants is underestimated in randomised-controlled studies in major depressive disorder.

\section{Implications for practice}

It is important to take into account the results derived from different study designs and the specific characteristics of patients when assessing the risk-benefit balance for drugs. Observational studies should be used as a necessary complement to RCTs in the evaluation of the risk-benefit ratio for a given drug. Once prescribed, strict monitoring of effectiveness and ADRs for a given drug is essential. The reporting of ADRs to pharmacovigilance system should be encouraged among practitioners. 


\section{CONTRIBUTORS}

Conceived and designed the experiments: CL, FN

Performed the experiments: NA, CL, JSA, FN

Analyzed the data: NA, CL, FN

Contributed reagents/materials/analysis tools: NA, CL, FN

Wrote the paper: NA, CL, FN

Revised the paper critically for important intellectual content: BF, JMB, EP, FM, DD

Final approval of the version to be published: NA, CL, FN

\section{DECLARATION OF INTERESTS}

There are no conflicts of interest regarding this paper. All authors have completed the Unified Competing Interest form at http://www.icmje.org/coi_disclosure.pdf (available on request from the corresponding author) and declare that (1) No authors have support from any company for the submitted work; (2) BF has relationships (board membership or consultancy or payment for manuscript preparation or travel/accommodation expenses covered/reimbursed) with Sanofi Aventis, Servier, Pierre-Fabre, MSD, Lilly, Janssen-Cilag, Otsuka, Lundbeck, Genzime, Roche, BMS who might have an interest in the work submitted in the previous 3 years; DD has relationships (board membership or consultancy or travel/accommodation expenses covered/reimbursed) with Servier, Lilly, Janssen-Cilag, Otsuka, Lundbeck, Astra Zeneca who might have an interest in the work submitted in the previous 3 years; FN has relationships (travel/accommodation expenses covered/reimbursed) with Servier, BMS, Lundbeck and Janssen who might have an interest in the work submitted in the previous 3 years; CL and FM are no conflicts of interests (3) No author's spouse, partner, or children have any financial relationships that could be relevant to the submitted work; and (4) none of the authors has any non-financial interests that could be relevant to the submitted work.

\section{ACKNOWLEDGEMENTS}

This work was supported by a local grant from Rennes CHU (CORECT: COmité de la Recherche Clinique et Translationelle). We would like to thank Angela Swaine Verdier for revising the English. 


\section{REFERENCES}

1. Gøtzsche P, Young A, Crace J: Does long term use of psychiatric drugs cause more harm than good? BMJ $2015 ; 350$

2. Gøtzsche P: Why I think antidepressants cause more harm than good. Lancet Psychiatry $2014 ; 1: 104-106$

3. Nutt DJ, Goodwin GM, Bhugra D, Fazel S, Lawrie S: Attacks on antidepressants: signs of deep-seated stigma? Lancet Psychiatry 2014; 1:102-104

4. Naudet F, Falissard B: Antipsychiatry and the antidepressants debate. Lancet Psychiatry 2014; 1:173-174

5. Ioannidis J: Adverse events in randomized trials: neglected, restricted, distorted, and silenced. Arch Intern Med 2009; 169:1737-9

6. Pitrou I, Boutron I, Ahmad N, Ravaud P: Reporting of safety results in published reports of randomized controlled trials. Arch Intern Med 2009; 169:1956-61

7. Tang E, Ravaud P, Riveros C, Perrodeau E, Dechartres A: Comparison of serious adverse events posted at ClinicalTrials.gov and published in corresponding journal articles. BMC Med. 2015; 13:189

8. Edwards IR, Aronson JK: Adverse drug reactions: definitions, diagnosis, and management. Lancet Lond. Engl. 2000; 356:1255-1259

9. Thomas SJ, Shin M, McInnis MG, Bostwick JR: Combination therapy with monoamine oxidase inhibitors and other antidepressants or stimulants: strategies for the management of treatment-resistant depression. Pharmacotherapy 2015; 35:433-449

10. The Joanna Briggs Institute: Joanna Briggs Institute Reviewers'Manual. 2011. Available from: http://joannabriggs.org/assets/docs/sumari/ReviewersManual-2011.pdf

11. Higgins J, Green S: Cochrane Handbook for Systematic Reviews of Interventions Version 5.0.2. 2008. Available from: http://www.cochrane-handbook.org 
12. Liberati A, Altman D, Tetzlaff J, Mulrow C, Gotzsche P: The PRISMA statement for reporting systematic reviews and meta-analyses of studies that evaluate health care interventions: explanation and elaboration. PLoS Med 6e1000100 2009;

13. Martin A, Young C, Leckman JF, Mukonoweshuro C, Rosenheck R, Leslie D: Age effects on antidepressant-induced manic conversion. Arch. Pediatr. Adolesc. Med. 2004; 158:773-780

14. Truman CJ, Goldberg JF, Ghaemi SN, Baldassano CF, Wisniewski SR, Dennehy EB, Thase ME, Sachs GS: Self-reported history of manic/hypomanic switch associated with antidepressant use: data from the Systematic Treatment Enhancement Program for Bipolar Disorder (STEP-BD). J. Clin. Psychiatry 2007; $68: 1472-1479$

15. Post RM, Altshuler LL, Leverich GS, Frye MA, Nolen WA, Kupka RW, Suppes T, McElroy S, Keck PE, Denicoff KD, Grunze H, Walden J, Kitchen CMR, Mintz J: Mood switch in bipolar depression: comparison of adjunctive venlafaxine, bupropion and sertraline. Br. J. Psychiatry 2006; 189:124-131

16. Shirazi E, Alaghband-Rad J: An open trial of citalopram in children and adolescents with depression. J. Child Adolesc. Psychopharmacol. 2005; 15:233-239

17. Tondo L, Vázquez G, Baldessarini RJ: Mania associated with antidepressant treatment: comprehensive meta-analytic review. Acta Psychiatr. Scand. 2010; 121:404-414

18. Goldberg J, Whiteside J: The association between substance abuse and antidepressant-induced mania in bipolar disorder: a preliminary study. J Clin Psychiatry 2002; 63:791-795

19. Baldessarini RJ, Faedda GL, Offidani E, Vázquez GH, Marangoni C, Serra G, Tondo L: Antidepressantassociated mood-switching and transition from unipolar major depression to bipolar disorder: a review. J. Affect. Disord. 2013; 148:129-135

20. Peet M: Induction of mania with selective serotonin re-uptake inhibitors and tricyclic antidepressants. Br. J. Psychiatry J. Ment. Sci. 1994; 164:549-550

21. Keup W, Apolito A, Olinger L, Schwartz M, Yachnes E: Inpatient treatment of depressive states with tofranil (imipramine hydrochloride). Am. J. Psychiatry 1959; 116:257-258 
22. Sachs GS, Nierenberg AA, Calabrese JR, Marangell LB, Wisniewski SR, Gyulai L, Friedman ES, Bowden CL, Fossey MD, Ostacher MJ, Ketter TA, Patel J, Hauser P, Rapport D, Martinez JM, Allen MH, Miklowitz DJ, Otto MW, Dennehy EB, Thase ME: Effectiveness of adjunctive antidepressant treatment for bipolar depression. N. Engl. J. Med. 2007; 356:1711-1722

23. Keller MB, Ryan ND, Strober M, Klein RG, Kutcher SP, Birmaher B, Hagino OR, Koplewicz H, Carlson GA, Clarke GN, Emslie GJ, Feinberg D, Geller B, Kusumakar V, Papatheodorou G, Sack WH, Sweeney M, Wagner KD, Weller EB, Winters NC, Oakes R, McCafferty JP: Efficacy of paroxetine in the treatment of adolescent major depression: a randomized, controlled trial. J. Am. Acad. Child Adolesc. Psychiatry $2001 ; 40: 762-772$

24. Canadian Medical Association or its licensors: Drug company experts advised staff to withhold data about SSRI use in children. CMAJ 2004; 170:783

25. Noury JL, Nardo JM, Healy D, Jureidini J, Raven M, Tufanaru C, Abi-Jaoude E: Restoring Study 329: efficacy and harms of paroxetine and imipramine in treatment of major depression in adolescence. The BMJ 2015; 351:h432027.

26. Avorn J: Two Centuries of Assessing Drug Risks. N. Engl. J. Med. 2012; 367:193-197

27. Healy D, Bechthold K, Tolias P. Antidepressant-induced suicidality: how translational epidemiology incorporating pharmacogenetics into controlled trials can improve clinical care. Pers Med 2014; 11: 79-88.

28. Naudet F, Maria AS, Falissard B: Antidepressant response in major depressive disorder: a meta-regression comparison of randomized controlled trials and observational studies. PloS One 2011; 6:e20811

29. Van der Lem R, Van der Wee NJA, Van Veen T, Zitman FG: Efficacy versus Effectiveness: A Direct Comparison of the Outcome of Treatment for Mild to Moderate Depression in Randomized Controlled Trials and Daily Practice. Psychother. Psychosom. 2012; 81:226-234

30. Naudet F, Falissard B, Boussageon R, Healy D: Has evidence-based medicine left quackery behind? Intern. Emerg. Med. 2015; 10:631-634 
Figure 1. PRISMA Chart

Figure 2. Forest plots

Forest plots are presented in ascending rate of manic switch.

1. Arms in observational studies

2. Arms with active treatment in RCTs

3. Arms with placebo in RCTs 


\section{Figure 1. Prisma Flow-chart}
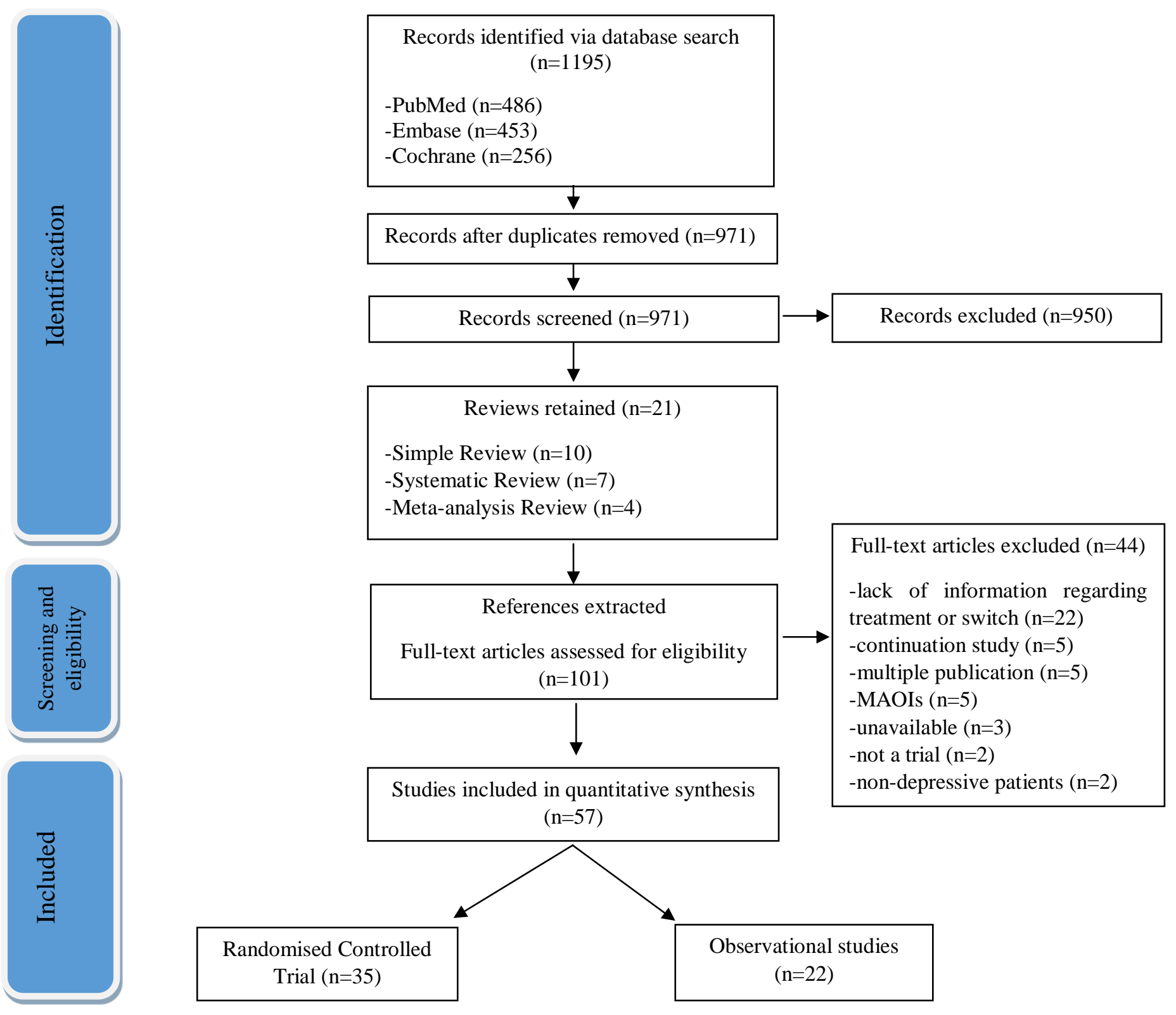
Study

Erfurth A 2002

Stoner SC 2001

Amsterdam JD 1998

Kupfer DJ 2001

Kupfer DJ 1988

Amsterdam JD 1998

Baldassano CF 1995

McConville BJ 1996

Leydberg 1959

Tierney 1995

Nasrallah HA 1982

Truman CJ 2007

Amsterdam JD 2004

Joffe RT 2002

Martin A 2004

Martin A 2004

Truman CJ 2007

Martin A 2004

Truman CJ 2007

Bottlender R 1998

Simpson SD 1991

Martin A 2004

Bottlender R 1998

Keup W 1959

Fonseca M 2006

Truman CJ 2007

Shirazi E 2005

Truman CJ 2007

Truman CJ 2007

Truman CJ 2007

Truman CJ 2007

Joffe RT 2002

Truman CJ 2007

Henry C 2001

Truman CJ 2007

Bottlender R 1998

Jann M 1982

Stoner SC 2001

Stoner SC 2001

Fogelson DL 1992

Random effects model

Heterogeneity: $I$-squared $=91.3 \%$, tau-squared $=0.0899, p<0.0001$
Proportion $\quad 95 \%-C l ~ W(r a n d o m)$

$0.00[0.00 ; 0.25] \quad 0.3 \%$

$0.00[0.00 ; 0.98] \quad 0.2 \%$

$0.00[0.00 ; 0.01] \quad 1.0 \%$

$0.02[0.00 ; 0.12] \quad 0.5 \%$

$0.03[0.01 ; 0.06] \quad 2.3 \%$

$0.04[0.01 ; 0.11] \quad 1.4 \%$

$0.05[0.00 ; 0.25] \quad 0.5 \%$

$0.05[0.00 ; 0.25] \quad 0.5 \%$

$0.06[0.02 ; 0.12] \quad 2.2 \%$

$0.06[0.01 ; 0.20] \quad 1.0 \%$

$0.06[0.03 ; 0.12] \quad 2.9 \%$

$0.07[0.02 ; 0.16] \quad 1.7 \%$

$0.08[0.02 ; 0.22] \quad 1.3 \%$

$0.08[0.02 ; 0.22] \quad 1.3 \%$

$0.09[0.08 ; 0.09] \quad 6.6 \%$

$0.09[0.09 ; 0.09] \quad 6.7 \%$

$0.09[0.02 ; 0.24] \quad 1.3 \%$

$0.11[0.11 ; 0.12] \quad 6.6 \%$

$0.12[0.03 ; 0.27] \quad 1.6 \%$

$0.12[0.03 ; 0.31] \quad 1.3 \%$

$0.12[0.02 ; 0.38] \quad 0.9 \%$

$0.13[0.12 ; 0.14] \quad 6.5 \%$

$0.14[0.03 ; 0.35] \quad 1.3 \%$

$0.14[0.06 ; 0.24] \quad 2.7 \%$

$0.15[0.03 ; 0.38] \quad 1.2 \%$

$0.16[0.11 ; 0.23] \quad 4.5 \%$

$0.17[0.06 ; 0.35] \quad 1.8 \%$

$0.17[0.12 ; 0.23] \quad 4.8 \%$

$0.17[0.09 ; 0.29] \quad 3.0 \%$

$0.18[0.11 ; 0.27] \quad 3.7 \%$

$0.19[0.14 ; 0.25] \quad 4.8 \%$

$0.20[0.11 ; 0.34] \quad 2.9 \%$

$0.23[0.14 ; 0.34] \quad 3.7 \%$

$0.24[0.11 ; 0.42] \quad 2.4 \%$

$0.32[0.26 ; 0.39] \quad 5.4 \%$

$0.34[0.24 ; 0.44] \quad 4.3 \%$

$0.40[0.23 ; 0.59] \quad 2.6 \%$

$0.50[0.07 ; 0.93] \quad 0.6 \%$

$0.50[0.07 ; 0.93] \quad 0.6 \%$

$0.62[0.24 ; 0.91] \quad 1.0 \%$

$0.14[0.12 ; 0.16] \quad 100 \%$ 
Study

Amsterdam J 1998 Amsterdam J 1998 Amsterdam JD 2005 Amsterdam JD 2005

Bauer M 1999

Brent D 2008

Cohn JB 1989

Danish University antidepressant Group 1990

De Wilde JE 1982

De Wilde JE 1982

Keller MB 2001

Nemeroff CB 2001

Normann C 2002

Normann C 2002

Young LT 2000

Dunner DL 2005

Baumhackl U 1989

Brent D 2008

Emslie GJ 2002

Keller MB 2001

Emslie G 2006

Browne MW 1963

Höhn R 1961

Vieta E 2002

Brown EB 2006

van Scheyen JD 1979

Danish University antidepressant Group 1990 Amsterdam JD 2008

Shelton RC 2004

Bauer M 1999

Tohen M 2003

Emslie GJ 1997

Bocchetta A 1993

Cohn JB 1989

Nemeroff CB 2001

Post RM 2006

Skarbek A 1963

Altshuler L 2006

Silverstone T 2001

Post RM 2006

Schaffer A 2006

Sachs GS 2007

McElroy SL 2010

Sachs GS 1994

Vieta E 2002

Klein DF 1966

van Scheyen JD 1979

Himmelhoch J 1991

Sachs GS 1994

Post RM 2006

\section{Random effects model}

\section{Events Total}

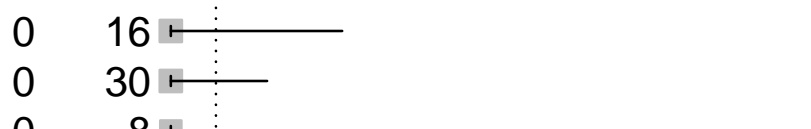

$\begin{array}{lc:}0 & 8 \leftleftarrows \\ 0 & 8 \rightleftarrows\end{array}$

$\begin{array}{lll}0 & 23 \rightleftarrows:-\end{array}$

0 168 F

030 上:

$0 \quad 56$

$0 \quad 15$ !

$0 \quad 15$ -

$0 \quad 95$ 上

35!

$0 \quad 20 \leftleftarrows$

$0 \quad 20$

0
0 11

21139

$1192+$

$166+$

$109+$

$93+$

$109 \div$

$35+$

$31+$

30

$8202+$

$25+$

46

43

$20 \div$

$\begin{array}{lll}1 & 19 \div \\ 5 & 8 6 \longdiv { \vdots }\end{array}$

348

15

1

339

$5 \quad 58$

17

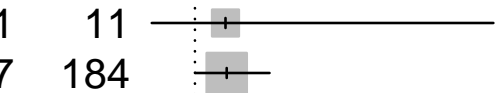

$\begin{array}{ll}7 & 75 \\ 5 & 5\end{array}$

5

110

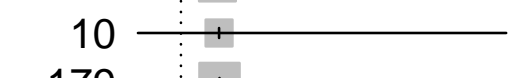

$\begin{array}{ll}8 & 179 \\ 3 & 118 \\ 1 & 8\end{array}$

1

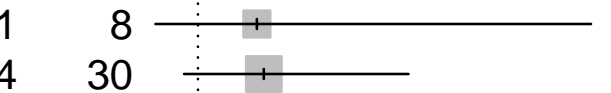

16

25

25
28

2

65

3892

\section{Proportion $\quad 95 \%-\mathrm{Cl}$ W(random)}

$0.00[0.00 ; 0.21] \quad 1.1 \%$

$0.00[0.00 ; 0.12] \quad 1.1 \%$

$0.00[0.00 ; 0.37] \quad 1.0 \%$

$0.00[0.00 ; 0.37] \quad 1.0 \%$

$0.00[0.00 ; 0.15] \quad 1.1 \%$

$0.00[0.00 ; 0.02] \quad 1.1 \%$

$0.00[0.00 ; 0.12] \quad 1.1 \%$

$0.00[0.00 ; 0.06] \quad 1.1 \%$

$0.00[0.00 ; 0.22] \quad 1.1 \%$

$0.00[0.00 ; 0.22] \quad 1.1 \%$

$0.00[0.00 ; 0.04] \quad 1.1 \%$

$0.00[0.00 ; 0.10] \quad 1.1 \%$

$0.00[0.00 ; 0.17] \quad 1.1 \%$

$0.00[0.00 ; 0.17] \quad 1.1 \%$

$0.00[0.00 ; 0.28] \quad 1.1 \%$

$0.00[0.00 ; 0.01] \quad 2.4 \%$

$0.01[0.00 ; 0.03] \quad 1.7 \%$

$0.01[0.00 ; 0.03] \quad 1.7 \%$

$0.01[0.00 ; 0.05] \quad 1.7 \%$

$0.01[0.00 ; 0.06] \quad 1.7 \%$

$0.03[0.01 ; 0.08] \quad 2.7 \%$

$0.03[0.00 ; 0.15] \quad 1.7 \%$

$0.03[0.00 ; 0.17] \quad 1.7 \%$

$0.03[0.00 ; 0.17] \quad 1.7 \%$

$0.04[0.02 ; 0.08] \quad 3.3 \%$

$0.04[0.00 ; 0.20] \quad 1.7 \%$

$0.04[0.01 ; 0.15] \quad 2.3 \%$

$0.05[0.01 ; 0.16] \quad 2.3 \%$

$0.05[0.00 ; 0.25] \quad 1.6 \%$

$0.05[0.00 ; 0.26] \quad 1.6 \%$

$0.06[0.02 ; 0.13] \quad 3.1 \%$

$0.06[0.01 ; 0.17] \quad 2.7 \%$

$0.07[0.00 ; 0.32] \quad 1.6 \%$

$0.07[0.01 ; 0.22] \quad 2.3 \%$

$0.08[0.02 ; 0.21] \quad 2.7 \%$

$0.09[0.03 ; 0.19] \quad 3.0 \%$

$0.09[0.00 ; 0.41] \quad 1.6 \%$

$0.09[0.05 ; 0.14] \quad 3.6 \%$

$0.09[0.04 ; 0.18] \quad 3.2 \%$

$0.10[0.03 ; 0.21] \quad 3.0 \%$

$0.10[0.00 ; 0.45] \quad 1.6 \%$

$0.10[0.06 ; 0.15] \quad 3.6 \%$

$0.11[0.06 ; 0.18] \quad 3.5 \%$

$0.12[0.00 ; 0.53] \quad 1.6 \%$

$0.13[0.04 ; 0.31] \quad 2.8 \%$

$0.19[0.04 ; 0.46] \quad 2.5 \%$

$0.24[0.09 ; 0.45] \quad 3.0 \%$

$0.25[0.11 ; 0.45] \quad 3.1 \%$

$0.29[0.04 ; 0.71] \quad 2.0 \%$

$0.29[0.19 ; 0.42] \quad 3.6 \%$

$0.05[0.04 ; 0.07] \quad 100 \%$

$\begin{array}{lllllllllllllllllll} & 0 & 0.1 & 0.2 & 0.3 & 0.4 & 0.5 & 0.6 & 0.7\end{array}$ 
Amsterdam JD 2005

Browne MW 1963

Emslie GJ 1997

Emslie GJ 2002

Höhn R 1961

Keller MB 2001

Klein DF 1966

Skarbek A 1963

Dunner DL 2005

Emslie G 2006

Nemeroff CB 2001

Cohn JB 1989

Tohen M 2003

Tohen M 2003

McElroy SL 2010

Sachs GS 2007

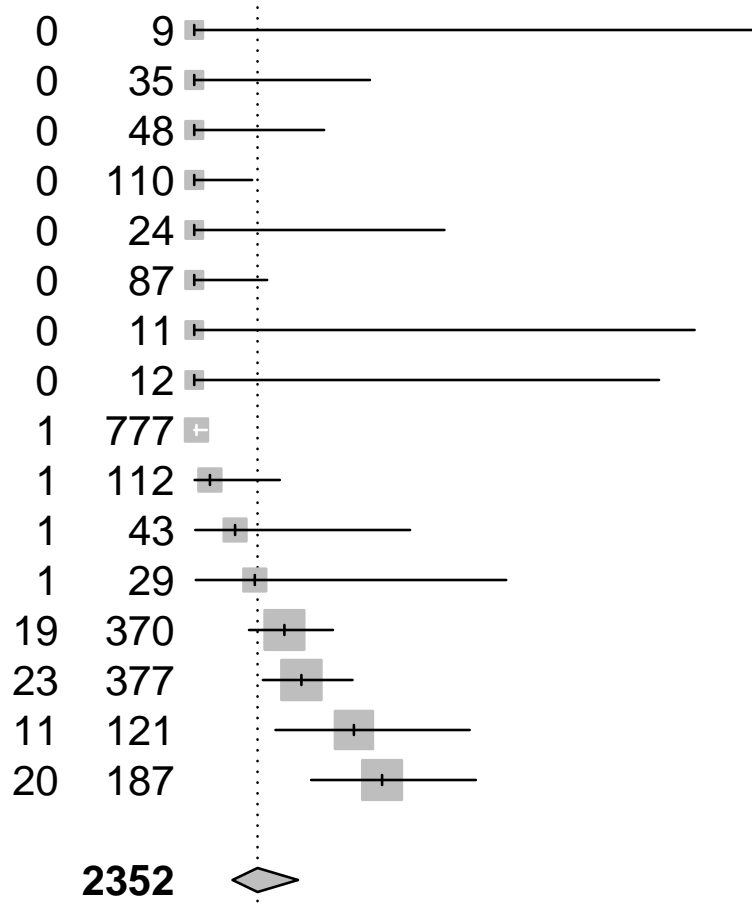

Random effects model

2352

$0.00[0.00 ; 0.34] \quad 2.8 \%$

$0.00[0.00 ; 0.10] \quad 2.9 \%$

$0.00[0.00 ; 0.07] \quad 2.9 \%$

$0.00[0.00 ; 0.03] \quad 2.9 \%$

$0.00[0.00 ; 0.14] \quad 2.8 \%$

$0.00[0.00 ; 0.04] \quad 2.9 \%$

$0.00[0.00 ; 0.28] \quad 2.8 \%$

$0.00[0.00 ; 0.26] \quad 2.8 \%$

$0.00[0.00 ; 0.01] \quad 4.9 \%$

$0.01[0.00 ; 0.05] \quad 4.9 \%$

$0.02[0.00 ; 0.12] \quad 4.8 \%$

$0.03[0.00 ; 0.18] \quad 4.8 \%$

$0.05[0.03 ; 0.08] \quad 14.7 \%$

$0.06[0.04 ; 0.09] \quad 15.0 \%$

$0.09[0.05 ; 0.16]-13.5 \%$

$0.11[0.07 ; 0.16] \quad 14.7 \%$

Heterogeneity: $I-$ squared $=62.4 \%$, tau - squared $=0.4199, p=0.0005$

$0.04[0.02 ; 0.06] \quad 100 \%$ 


\section{Table 1. Study characteristics}

\begin{tabular}{|c|c|c|}
\hline & $\operatorname{RCT}(n=35)$ & Observational studies $(n=22)$ \\
\hline Year of study & $2001(1961 ; 2010)$ & 1998 (1959; 2007) \\
\hline \multicolumn{3}{|l|}{ Design } \\
\hline Prospective & $35(100 \%)$ & $13(59,1 \%)$ \\
\hline Retrospective & & $9(40,9 \%)$ \\
\hline \multicolumn{3}{|l|}{ Blinded } \\
\hline Double & $32(91,4 \%)$ & - \\
\hline Simple & $1(2,9 \%)$ & - \\
\hline Open label & $2(8,7 \%)$ & $22(100 \%)$ \\
\hline Study duration (weeks) & $8(4 ; 182)$ & $12(4 ; 40)$ \\
\hline Quality assesment (Score/100) & $83,3(0 ; 100)$ & $62,5(6,3 ; 81,3)$ \\
\hline \multicolumn{3}{|l|}{ Evaluation of manic switch } \\
\hline Clinical judgment & $35(100 \%)$ & $21(95,5 \%)$ \\
\hline Diagnosis change & - & $1(4,5 \%)$ \\
\hline
\end{tabular}

Quantitative variables : median (Min ; Max)

Qualitative variables: N (\%)

Quality score is computed out of 100 points from the two Joanna Brigs Institute instruments 
Table 2. Arm characteristics

\begin{tabular}{|c|c|c|}
\hline & RCT & Observational Studies \\
\hline Number of arms & 66 & 40 \\
\hline \multicolumn{3}{|l|}{ Treatment } \\
\hline SSRI & $22(33,3 \%)$ & $22(55 \%)$ \\
\hline SNRI & $7(10,6 \%)$ & $1(2,5 \%)$ \\
\hline IP & $17(25,8 \%)$ & $8(20 \%)$ \\
\hline Other classes & $2(3,05 \%)$ & $7(17,5 \%)$ \\
\hline All classes & $2(3,05 \%)$ & $2(5 \%)$ \\
\hline Placebo & $16(24,2 \%)$ & $0(-)$ \\
\hline Number of patients entering analysis & 6244 & 76544 \\
\hline \multicolumn{3}{|l|}{ Previous antidepressant resistance } \\
\hline Yes & $4(6,1 \%)$ & $4(10 \%)$ \\
\hline No & $62(93,9 \%)$ & $36(90 \%)$ \\
\hline Patient type & $N A=6$ & $N A=3$ \\
\hline Inpatient & $16(36,7 \%)$ & $8(21,6 \%)$ \\
\hline Outpatient & $39(65 \%)$ & $26(70,3 \%)$ \\
\hline Out and inpatient & $5(8,3 \%)$ & $3(8,1 \%)$ \\
\hline \multicolumn{3}{|l|}{ Diagnosis } \\
\hline Unipolar disorder & $22(33,34 \%)$ & $9(22,5 \%)$ \\
\hline Bipolar disorder & $35(53,03 \%)$ & $29(72,5 \%)$ \\
\hline Unipolar and bipolar & $9(13,63 \%)$ & $2(5 \%)$ \\
\hline \multicolumn{3}{|l|}{ Age classes } \\
\hline Children and adolescent & $11(16,7 \%)$ & $3(7,5 \%)$ \\
\hline Adults & $55(83,3 \%)$ & $33(82,5 \%)$ \\
\hline Both & $0(-)$ & $4(10 \%)$ \\
\hline Proportion of women & $63,5 \%(N A=6)$ & $66,5 \%(N A=17)$ \\
\hline
\end{tabular}

Qualitative variable: N (\%)

$\mathrm{NA}=$ not available or missing data

SSRI $=$ Selective Serotonin Reuptake Inhibitor

SNRI=Serotonin-Norepinephrine Reuptake Inhibitor

$\mathrm{IP}=$ Imipraminics 
Table 3. Meta-regression analysis. Main analysis

\begin{tabular}{|c|c|c|}
\hline \multicolumn{3}{|c|}{ Main analysis } \\
\hline & Coefficient [95\% Confidence Interval] & $\mathrm{p}$ value \\
\hline RCT (Ref = observational) & $\mathbf{0 , 5 3}[0,32$ to 0,87$]$ & 0,013 \\
\hline \multicolumn{3}{|l|}{ Treatment $($ Ref $=$ placebo $)$} \\
\hline SSRI & $1,25[0,86$ to 1,81$]$ & 0,237 \\
\hline SNRI & $1,74[1,06$ to 2,86$]$ & 0,029 \\
\hline IP & $1,85[1,22$ to 2,79$]$ & 0,004 \\
\hline Other classes & $1,58[1,08$ to 2,31$]$ & 0,017 \\
\hline All classes & $1,21[0,83$ to 1,78$]$ & 0,326 \\
\hline Previous antidepressant resistance $(\operatorname{Ref}=\mathrm{no})$ & $0,78[0,30$ to 2,05$]$ & 0,619 \\
\hline \multicolumn{3}{|l|}{ Patient type (Ref= outpatient) } \\
\hline Out and inpatient & $1,24[0,63$ to 2,42$]$ & 0,534 \\
\hline Inpatient & $1,97[0,89$ to 4,37$]$ & 0,095 \\
\hline \multicolumn{3}{|l|}{ Age classes (Ref $=$ children and adolescent) } \\
\hline Adults & $0,2[0,07$ to 0,59$]$ & 0,004 \\
\hline Both & $3,83[0,92$ to 15,90$]$ & 0,065 \\
\hline \multicolumn{3}{|l|}{ Diagnosis (Ref= unipolar) } \\
\hline Bipolar disorder & $\mathbf{2 0 , 5 8}[8,41$ to 50,31$]$ & $<0,001$ \\
\hline Unipolar and bipolar & $1,71[0,58$ to 5,02$]$ & 0,33 \\
\hline Year of study & $0,97[0,96$ to 0,98$]$ & $<0,001$ \\
\hline Study duration & $1,01[1,00$ to 1,03$]$ & 0,011 \\
\hline Proportion of women & $1[0,98$ to 1,02$]$ & 0,973 \\
\hline
\end{tabular}

SSRI $=$ Selective Serotonin Reuptake Inhibitor

SNRI=Serotonin-Norepinephrine Reuptake Inhibitor

$\mathrm{IP}=$ Imipraminics 